\title{
PROPAGACION VEGETATIVA DE Bactris gasipaes Bailey (PLJUAYO)
}

\author{
David Panduro Rengifo *
}

\section{RESUMEN}

En el Centro de Investigación y Enseñanza Forestal de la Facultad de Ingeniería Forestal de la Universidad Nacional de la Amazonía Peruana, se evaluó la propagación vegetativa de Bactris gasipaes Bailey, con el objetivo de determinar la capacidad de enraizarniento de los hijuelos, para lo cual se empleó tres rangos de tamaño y cuatro períodos de almacenamiento de los hijuelos después de ser aislados de la palma madre.

Se aplicó la técnica del experimento factorial 3 x 4 arreglado al Diseño de Bloques al Azar.

Sin ser interactuantes, ambos factores influyeron significativamente en la sobrevivencia de los hijuelos, encontrándose las mejores respuestas con combinaciones de 0.2 a $0.4 \mathrm{~m}$. de altura con 2 y 4 días de almacenamiento con $40 \%$ de prendimiento. No obstante, la sobrevivencia se considera relativamente baja, lo que sugiere la existencia de factores aún no determinados que limitan la aplicación de la técnica de propagación ensayada.

\section{SUMMARY}

A tes of vegetative reproduction of Bactris gasipaes Bailey (Pejibaye Palm) using basal shoot it was done at the Education and Research Centro of the Faculty of Forestry at Iquitos city.

As statistical method, the tecnhique of factorial experiment of $3 \times 4$ using the random system was used. Here the size of the scedlings and the storing time were considered as factors. The objetive of the research was to determine the optimal size of the seedlings and the storing time that will allow a great numher of living plants, using the capacity of rooting of these plants.

The research results indicate that voth factors influnced in the variation of the rooting, with the advantage for the basal shoot between $0.10-0.40 \mathrm{~m}$. of height with 2 to 4 days of storing, showing the mayor success. Also, it is possihle to assure the witch the different test used, the one with more success obtained $40 \%$ of rooting, putting in evidence the presence of another factors which difficult the control and deteriorate the surviving capacity of the Pejibaye Palm basal shoot.

* Investigador IIAP. 


\section{INTRODUCCION}

Bactris gasipaes Bailey (Pijuayo), es una palmera utilizada en la alimentación humana y animal, en construcciones rústicas y hasta en medicina vernacular; características que la califican como base para el desarrollo de una agroindustria que, a su vez, tendría el efecto de transformar la agricultura migratoria en sedentaria; esta transformación contribuiría a disminuir la destrucción de bosques con fines agrícolas.

El pijuayo frecuentemente es autoincompatible, esto lo hace una especie predominantemente alógama obligatoria; característica que no permite la multiplicación eficiente de genotipos deseables por vía sexual.

La propagación vegetativa como alternativa, permite establecer plantaciones de pijuayo con características deseables, utilizando como semillas los rebrotes basales.

Gonzáles (1983) afirma que esta especie ha sido cultivada desde hace varios siglos por numerosas comunidades indígenas de América del Sur y Central, y no se ha podido determinar con exactitud su lugar de origen. Esta palmera probablemente se originó en la selva Amazónica colindante con la parte oriental de la Cordillera de los Andes, donde hay fuerte pluviosidad y altas temperaturas.

Camacho 1972 menciona que esta palmera parece adaptarse a un amplio rango de condiciones ecológicas dentro de la zona tropical. En Costa Rica se la encuentra prácticamente en todos los climas y clases de suelos, desde el nivel del mar hasta 1,200 m. de altura, con regímenes muy diferentes de precipitación pluvial. Sin embargo, su crecimiento y producción son marcadamente mejores en lugares con una elevación de 200 a $800 \mathrm{~m}$. con lluvia durante todos los meses del ano. Según Popende y Jiménez (1921) la precipitación adecuada es de 2,500 mm anuales; Johannenssen (1966), indica que en lugares altos y con estación seca prolongada el crecimiento es lento y los frutos son más pequeños.

Camacho (1972, menciona que para producir las características deseables de los pijuayos de calidad superior, la propagación ha de hacerse mediante métodos asexuales, utilizando brotes o hijos basales de las plantas adultas que se desea propagar; pero este método, hasta el momento, en el campo no ha dado buenos resultados, obteniéndose un porcentaje muy bajo de sobrevivientes.

Gonzales (1983) indica que la formación de renuevos basales que darán origen a nuevos tallos, empiezan por lo general, dentro del primer año después de la germinación de la semilla, en el nudo inferior del tallo a raíz del suelo; Mora, Urpi y Tosi (1983) dan a conocer que en las plantaciones juveniles, las yemas auxiliares, aproximadamente en número de doce, están situadas a la altura del rizoma. 
En una evaluación de plantas de pijuayo en Turrialba, Camacho (1972) encontró que el $89 \%$ de las palmeras tenían de 5 a 12 brotes basales; a este respecto

Pérez (comunicación personal), encontró un promedio de 4.7 hijuelos basales por planta al evaluar 137 introducciones procedentes del Brasil y Colombia. Según Mora - Urpi 4(198 1) el número de brotes basales depende de la variedad y de las condiciones de luz.

Pérez (1983) menciona que los hijuelos aislados del pijuayo son de escasa resistencia a la deshidratación o al exceso de lluvia, lo cual contribuye al bajo rendimiento de supervivencia, por lo tanto su utilización propagativa es restringida. Pérez (1985) obtuvo $3.4 \%$ de prendimiento de un total de 480 hijuelos basales trasplantados.

Mora-Urpi y Tosi (1983) obtuvieron $10 \%$ de rendimiento señalando que las plantas logradas así tienden a producir menos frutos, Gonzales y Domínguez (1972) emplearon hijuelos sin vástago y hasta con $100 \mathrm{~cm}$. de longitud y obtuvieron, luego de 45 días de evaluación, $23.28 \%$ de prendimiento.

Fournier (s.f.), indica que para separar los hijuelos de la planta madre, deben tener entre $7.5 \mathrm{~cm}$. y $15 \mathrm{~cm}$. de grosor. Según Popende y Jiménez (1921), se debe utilizar, para este fin, hijos con diámetros de unos $8 \mathrm{~cm}$. en la base y de $1.80 \mathrm{~m}$. de altura con las hojas recortadas. Sin embargo, todavía no se ha logrado desarrollar un método de propagación vegetativa que asegure porcentajes satisfactorios de sobrevivientes. Patiño (1979), menciona que los renuevos basales, entre 50 y $100 \mathrm{~cm}$. de altura son los que mejor se comportaron en un experimento.

Popende y Jiménez (1921) opinan que el pijuayo no parece ser exigente en cuanto se refiere a las prácticas culturales; porque las plantas que alcanzan los $2.5 \mathrm{~m} .63 \mathrm{~m}$. de altura no parecen sufrir mucho con la presencia de malezas, sin embargo es necesario hacer deshierhos periódicamente, pero Patiño (1979) indica que dentro de las malezas que frecuentan al cultivo de pijuayo están las gramíneas retrasan el desarrollo inicial de las plantas jóvenes, debido a la competencia de nutrientes; este retraso se manifiesta en el amarillamiento (clorosis) que se presenta en el área foliar a consecuencia de falta de nitrógeno en el cultivo juvenil, esto quiere decir que esta era no es tolerante a la competencia de las gramíneas y que, por o, no es aconsejable la combinación pijuayo gramíneas. 
Patiño (1979), indica que el pijuayo se adapta a muchos tipos suelos, pero prospera mejor en aquellos profundo y bien drenado. La capa freática muy superficial inhibe la producción de frutos, aún es preferible sembrarlos en suelos pobres de loma que en terrenos anegadizos aunque sean de mayor riqueza nutricional. Dejar más de m. entre plantas, es desperdicio de terreno. A este respecto, (1972), indica que los agricultores utilizan distancias de siembra desde $4 \times 4 \mathrm{~m}$. hasta $8 \times 8 \mathrm{~m}$. de espaciamiento, dejando desarrollar de 3 a 5 hijuelos de cada planta.

\section{MATERIALES Y METODOS}

\section{UBICACIÓN Y CARACTERÍSTICAS DEL ÁREA}

Los trabajos se efectuaron en el Centro de Investigación y Enseñanza Forestal (CIEFOR) Puerto Almendras, propiedad de la UNAP, ubicado junto al caserío Puerto Almendras.

El área es accesible desde Iquitos por carretera, aproximadamente $22 \mathrm{Km}$., en dirección Suroeste y, por vía fluvial por el río Nanay aproximadamente en 45' en bote deslizador con motor fuera de borda de 40 H.P. partiendo de Morona Cocha.

El clima es cálido y lluvioso. Los datos promedios registrados en el observatorio metereológico de Zúngaro Cocha durante el período 1975 - 1985 por el Servicio Nacional de Metereología e Hidrología, son los siguientes: Temperatura media mensual: $26^{\circ} \mathrm{C}$, precipitación media anual: 2,948.5 mm., meses más pluviosos: abril, mayo y diciembre, meses más secos: enero, junio y agosto, humedad relativa promedio anual: $86.69 \%$.

Esta localidad se encuentra en la formación bosque húmedo tropical (b.h.t.) de acuerdo a la clasificación de zonas divididas de Holdrige (ONERN 1976).

El lugar en donde se ubicaron las parcelas, está dentro de la zona de influencia de la carretera Iquitos-Nauta, cuyos suelos fueron evaluados por Calderon y Castillo (1981) informando que esta gran zona tiene terrenos muy profundos, franco arcillosos, friables, con pH de 5.0 a 5.3 y con 70 a $80 \%$ de aluminio cambiable, el relieve es de suavemente ondulado a llano, de drenaje moderado. 
ME TOD O

\section{Descripción del ensayo}

Se aplicó la técnica del experimento factorial de 3 x 4, arreglados al diseño de bloques al azar con 3 repeticiones considerándose dos factores y tres niveles.

Factor A: $\quad$ Tamaño de hijuelo

Niveles

$\begin{array}{lllll}\mathrm{a}_{0} & = & 0.20 \mathrm{~m} . & \mathrm{a} & 0.40 \mathrm{~m} . \\ \mathrm{a}_{1} & = & 0.41 \mathrm{~m} . & \mathrm{a} & 0.60 \mathrm{~m} . \\ \mathrm{a}_{2} & = & 0.61 \mathrm{~m} . & \mathrm{a} & 0.80 \mathrm{~m} .\end{array}$

Factor B: $\quad$ Almacenamiento (tiempo previo a la plantación)

Niveles

b0 $=\quad$ sin almacenamiento (0 días después del aislamiento).

b1 $=\quad$ con 2 días de almacenaje ( 2 días después de aislamiento).

b2 $=\quad$ con 4 días de almacenaje (4 días después del aislamiento).

Los hijuelos fueron almacenados en el suelo bajo cobertura arbórea, cubriéndolos con hojas de palmas. Combinando los niveles se obtuvo 12 tratamientos, que se los dispuso al azar dentro de los bloques. Los hijuelos se los separó de la palma madre cortándolos con machete y tratando de extraerlos con el menor daño posible.

Cada uno de los hijuelos fueron sembrados previo corte de la parte terminal. El corte, se efectuó en el mismo sitio de la medición previa a la separación de la palma madre; esto permitió la observación de la aparición y el desarrollo de la yema terminal de hijuelo. Se regó, sólo en el momento del trasplanté con regadera de grano grueso. Las parcelas se deshierbaron en tres oportunidades utilizando machetes. Se emplearon 30 hijuelos por tratamiento.

Se realizó en cuatro oportunidades, a las 15, 30, 45 días según lo planificado y adicionalmente se realizó el último chequeo a los 11 meses de 
plantados. La información que se registró fue: fecha de siembra, fecha de control, número de plantas prendidas, número de hijuelos muertos. Se consideraba como enraizado o prendido al que permanecía con hojas verdes, y que posteriormente emitían renuevos foliares hasta la finalización del ensayo (330 días). El último chequeo tuvo lugar en medio de una densa invasión de gramíneas de elevada altura; puesto que después de la penúltima evaluación, el experimento no fue deshiervado.

\section{Análisis de la varianza}

Los datos de prendimiento se expresaron en porcentajes, los que tr4mstrmaron al seno del arco, $\sqrt{ }$ porcentaje, calzada (1970), como $\mathrm{n}<50$, el porcentaje cero se contó como $1 / 4 \mathrm{n}$, antes de transformar a ángulos, .Snedecor y Cochrán (1981).

Con los datos transformados se hizo el análisis de varianza y pruebas de comparación de las medias de tratamientos, aplicando el método de comparaciones múltiples de Duncan, se efectuó la comparación de los promedios de tratamiento para identificar las diferencias significativas. Asimismo, los niveles de los factores se los comparó mediante este método y se elaboró gráficas de barras para observar las diferencias numéricas obtenidas entre tratamientos en cuanto a prendimiento.

Además se elaboró la superficie de respuesta que involucra el experimento factorial (gráfico 2). 


\section{RESULTADOS}

\section{Cuadro 1}

PORCENTAJE DE HIJUELOS DE Guilielma Gasipaes PRENDIDOS AL FINAL DEL ENSAYO (330 DÍAS DESPUÉS DE LA PLANTACIÓN)

FACTORES

BLOQUES

PROMEDIO

DE TRATAMIENTO

TAMAÑO - A ALMACENAJE I II II

\begin{tabular}{clllll} 
& $\mathrm{b}_{1}$ (0 días) & 30.23 & 25 & 40 & 33.30 \\
$\mathrm{a}^{0}$ & $\mathrm{~b}_{1}$ (2 días) & 70 & 10 & 40 & 40.00 \\
$(0.20-0.40 \mathrm{~m})$ & $\mathrm{b}_{2}$ (4 días) & 50 & 30 & 40 & 40.00 \\
& $\mathrm{~b}_{3}$ (6 días) & 20 & 0 & 10 & 10.00 \\
& & & & & \\
& $\mathrm{~b}_{1}$ (0 días) & 30 & 20 & 40 & 30.00 \\
$\mathrm{a}^{1}$ & $\mathrm{~b}_{1}$ (2 días) & 20 & 50 & 20 & 30.00 \\
$(0.41-0.40 \mathrm{~m})$ & $\mathrm{b}_{2}$ (4 días) & 30 & 0 & 10 & 13.33 \\
& $\mathrm{~b}_{3}$ (6 días) & 10 & 30 & 0 & 13.33 \\
& $\mathrm{~b}_{4}$ (0 días) & 20 & 10 & 10 & 13.33 \\
& & & & & \\
$\mathrm{a}^{2}$ & & & & & \\
$(0.61-0.80 \mathrm{~m})$ & $\mathrm{b}_{1}$ (2 días) & 0 & 50 & 50 & 33.33 \\
& $\mathrm{~b}_{2}$ (4 días) & 0 & 0 & 0 & 0.00 \\
& $\mathrm{~b}_{3}$ (6 días) & 10 & 0 & 0 & 3.33 \\
\hline
\end{tabular}




\section{Cuadro 2}

\section{DATOS DEL CUADRO 1 TRANSFORMADOS AL ARCO SENO PORCENTAJE}

\begin{tabular}{|c|c|c|c|c|c|}
\hline \multicolumn{2}{|c|}{ FACTORES } & \multicolumn{3}{|c|}{$\begin{array}{c}\text { PROCEDIMIENTOS } \\
\text { BLOQUES }\end{array}$} & \multirow[t]{2}{*}{ TOTALES } \\
\hline TAMAÑO - A & ALMACENAJE -B & I & II & III & \\
\hline \multirow{4}{*}{$\begin{array}{c}\mathrm{a}^{0} \\
(0.20-0.40 \mathrm{~m})\end{array}$} & $\mathrm{b}_{0}$ (0 días) & 39.23 & 25.56 & 39.23 & 105.02 \\
\hline & b1 (2 días) & 56.79 & 18.44 & 39.23 & 114.46 \\
\hline & b2 (4 días) & 45.00 & 33.21 & 39.23 & 117.44 \\
\hline & b3 (6 días) & 26.56 & 9.10 & 18.44 & 54.10 \\
\hline \multirow{5}{*}{$\begin{array}{c}\mathrm{a}_{1} \\
(0.41-0.40 \mathrm{~m})\end{array}$} & b1 (0 días) & 32.21 & 26.56 & 39.23 & 99.00 \\
\hline & $\mathrm{b}_{1}$ (2 días) & 26.56 & 45.00 & 26.56 & 98.12 \\
\hline & $\mathrm{b}_{2}$ (4 días) & 33.21 & 9.10 & 18.44 & 60.75 \\
\hline & $\mathrm{b}_{3}$ (6 días) & 18.44 & 33.21 & 9.10 & 60.75 \\
\hline & bo (0 días) & 26.56 & 18.44 & 18.44 & 63.44 \\
\hline \multirow{3}{*}{$\begin{array}{c}\mathrm{a}_{2} \\
(0.61-0.80 \mathrm{~m})\end{array}$} & b1 (2 días) & 9.10 & 45.00 & 45.00 & 99.10 \\
\hline & b2 (4 días) & 9.10 & 9.10 & 9.10 & 27.30 \\
\hline & b3 (6 días) & 18.44 & 9.10 & 9.10 & 36.64 \\
\hline \multicolumn{2}{|c|}{ TOTAL BLOQUES } & 342.20 & 282.82 & 311.10 & 936.12 \\
\hline
\end{tabular}




\section{Cuadro 3}

\section{ANALISIS DE VARIANZA}

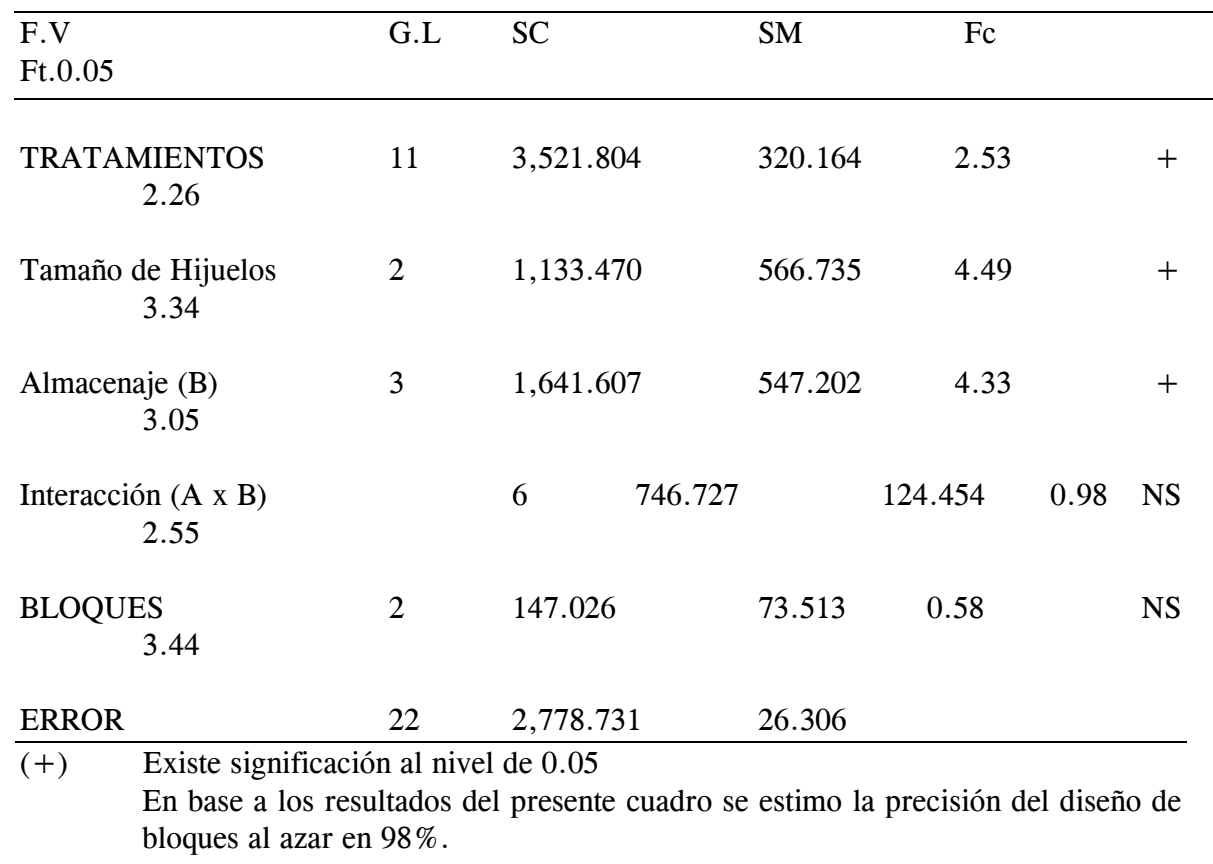




\section{Cuadro 4}

COMPARACIÓN E INTERPRETACIÓN DE LA PRUEBA DE F PARA LOS FACTORES

\section{FACTORES}

PROMEDIOS

SIGNIFICACION $(+)$

Tamaño de Hijuelos

$\mathrm{a} 0$

$\mathrm{a}_{1}$

a2
32.585

26.552

18.873
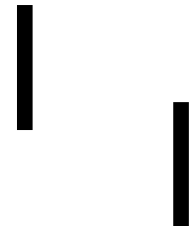

Tiempo de Almacenamiento

$\mathrm{b}_{0}$

34.631

29.718

$\mathrm{b}_{2}$

22.832

$\mathrm{b}_{3}$

16.832
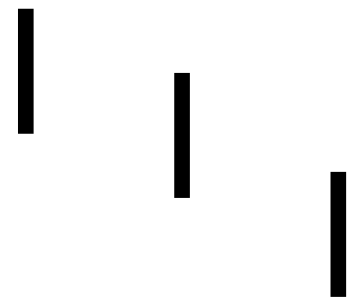

(+) La línea subraya los promedios que no resultaron con diferencia significativa a un nivel de $5 \%$ 


\section{Cuadro 5}

PRESENTACION E INTERPRETACION DE LAS PRUEBAS DE COMPARACION ESTADISTICAS PARA LOS FACTORES DE HIJUELOS Y TIEMPO DE ALMACENAMIENTO

5.1 FACTOR DE ALMACENAJE (B)

TAMAÑO DE HIJUELO

5.1A Sin almacenaje (b1) Código

Promedio

Sognif. $(+)$

5.1b Con 2 días de almac. (b 1$)$

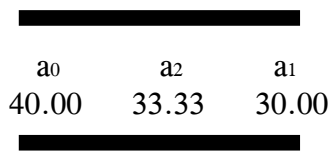

5.1c Con 4 días de almac. ( $\left.b_{2}\right)$

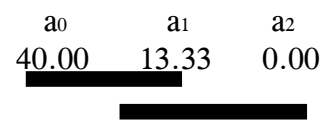

5.1d Con 6 días de almac. ( $\left.b_{3}\right)$

$\begin{array}{ccc}\mathrm{a}_{0} & \mathrm{a}_{1} & \mathrm{a}_{2} \\ 33.33 & 30.00 & 13.33\end{array}$

$\begin{array}{ccc}13.33 & 10.00 & 3.33\end{array}$

5.1 FACTOR DE ALMACENAJE (B)

TAMAÑO DE HIJUELO

5.2a De 20 a $40 \mathrm{~cm}$. (a)

$\begin{array}{cccc}\mathrm{b}_{1} & \mathrm{~b}_{2} & \mathrm{~b}_{0} & \mathrm{~b}_{3} \\ 40.00 & 40.00 & 33.33 & 10.00\end{array}$

5.2b De 41 a $60 \mathrm{~cm}$. (a1)

$\begin{array}{llll}b_{0} & b_{1} & b_{2} & b_{3}\end{array}$

$\begin{array}{llll}30.00 & 30.00 & 13.33 & 13.33\end{array}$

5.2c De 61 a $80 \mathrm{~cm} .\left(\mathrm{a}_{2}\right)$

$\begin{array}{cccl}\mathrm{b}_{1} & \mathrm{~b}_{0} & \mathrm{~b}_{3} & \mathrm{~b}_{2} \\ 33.33 & 13.33 & 3.33 & 0.00\end{array}$

(+) Los promedios unidos por una misma raya no tiene diferencia estadística significativa, según la Prueba $\mathrm{F}$ al nivel de 0,05 


\section{DISCUSION}

El porcentaje máximo de prendimiento logrado en el experimento es de $40 \%$, tal como se observa en el cuadro 1 . El tiempo de almacenamiento, al que se sometió a los hijuelos de pijuayo antes de la siembra, y el tamaño mismo del hijuelo, influyen en el prendimiento de estos; hechos que se deducen al analizar los resultados que contiene el cuadro 3 y que amerita realizar mayor estudio.

En el cuadro 5 se presenta los resultados del prendimiento obtenido cuando se utiliza diferentes tamaños de hijuelos de pijuayo por cada tiempo de almacenamiento en particular, y se evidencia que el tamaño del hijuelo no influye en la diferenciación del rendimiento cuando los hijuelos son plantados el mismo día; es decir sin almacenamiento, la misma tendencia se observa cuando los hijuelos son plantados con 2 y 6 días de almacenamiento y que el mayor prendimiento se obtendrá cuando los hijuelos son sembrados hasta con 2 días de almacenamiento y que las variaciones que se puedan presentar en las repuestas no son diferentes con un 5 por ciento de significación estadística (cuadro 4).

Esta aseveración se puede verificar analizando los resultados de las comparaciones que se presentan en el cuadro 5; razón por la cual se deduce que se puede utilizar los hijuelos que tengan una altura comprendida entre 20 a 80 cm., y almacenarlos hasta 2 días, sin que las respuestas difieran.

El tamaño del hijuelo que se va a utilizarse puede variar incluso hasta los $100 \mathrm{~cm}$ de altura, como lo recomienda Patiño (1979). En todo caso la elección del tamaño, estará en función de las facilidades con que se cuente; pero los hijuelos cuyos tamaños oscilen entre 20 a $40 \mathrm{~cm}$ de altura pueden soportar 4 días de almacenamiento sin variar significativamente el porcentaje de prendimiento (gráfico 2).

Con la propagación vegetativa (método asexual) utilizando hijuelos o brotes basales se obtuvo porcentajes de prendimiento muy bajos, Camacho (1972). Gonzales y Domínguez (1977) encontraron que el porcentaje de prendimiento a los 45 días de evaluación fue de 23.38 por ciento, trabajando con plantas hasta con $100 \mathrm{~cm}$ de altura.

Estos porcentajes logrados son inferiores si se compara con los resultados obtenidos en el presente trabajo, en el que se obtuvo 40 por ciento de prendimiento promedio; bajo condiciones en extremo desventajosas y, en el mismo lapso de tiempo (gráfico 3).

Sin embargo, se intuye que es posible aumentar el porcentaje de prendimiento, mejorando al máximo el manipuleo del material experimental, efectuando un control adecuado de las malezas, en especial de las gramíneas, refinando la técnica de extracción de hijuelos, de tal manera que el laceramiento 
en éste sea mínimo, buscando el mejor modo de desinfectar y cicatrizar el corte, para evitar en lo posible la pudrición del rizoma. Por último, es importante la búsqueda de una sustancia que influya en el incremento del enraizamiento $\mathrm{y}$, de ser posible, en su aceleración.

En la evaluación del experimento a algunas palmas de pijuayo plantadas se las dio por muertas, pero posteriormente se registró el brote de una nueva palma como consecuencia del desarrollo de una de las yemas en el rizoma para descubrir la respuesta al enraizamiento en función del número de yema, que permita predecir la posibilidad de enraizamiento, las que en este caso se contaron hasta nueve.

En el cuadro 5 se observa que los promedios de enraizamiento digieren notoriamente entre tratamientos y que la magnitud de 26.86 ciento no se determinó como significativa al 5 por ciento del nivel de significación estadística, utilizando como criterio la prueba de F. similar particularidad se presenta en los resultados del cuadro 5, en el que la diferencia del 20 por ciento no es estadísticamente significativa, existiendo una variabilidad de las respuestas que fluctúan de $\mathrm{O}$ a 70 por ciento, que se atribuye a factores no controlados que influyeron en las respuestas.

La eficiencia del bloqueo realizado fue 2 por ciento menor en comparación al uso de un diseño completamente al azar. Es posible que la variabilidad del suelo, la invasión de malezas o el manipuleo del material experimental influyeron en los resultados, sin descartar otras fuentes causales de variación no controladas. Así, las gramíneas se consideran como malezas, en función al desarrollo del pijuayo, por retrazar el desarrollo de las plantas jóvenes cuando compiten por los nutrientes existentes en el suelo, tal como determinó Patiño (1979).

Después de los 45 días de plantación, en el área experimental no se realizó la limpieza de malezas, dando paso a la invasión de gramíneas; sin embargo, la posibilidad que las gramíneas interfieran en el desarrollo del pijuayo es similar en el lugar experimental; en consecuencia, en las plantas jóvenes del pijuayo se presenta la misma posibilidad de vivir o morir. En el experimento se observó que los mayores índices de mortalidad por parcela acontecen en áreas contiguas formando grupos.

Entre otras causales de variación que no se han controlado se encuentran las que provienen del substrato, que pueden transmitir infección micótica y bacteriana al rizoma, produciendo su pudrición en menos de 30 días. El clima, que por efecto de la insolación, acelera la transpiración tanto en los hijuelos almacenados como en los sembrados; y la anegación, que influye en la respiración; (en el tiempo de la experimentación octubre - diciembre. llovió constantemente, lo cual es frecuente). 


\section{CONCLUSIONES}

1. El 40 por ciento de prendimiento de hijuelos basales de Guilielma gasipaes Bailey, obtenido en el presente experimento, a pesar de ser un resultado bajo, resulta satisfactorio por los antecedentes en propagación vegetativa conocidos.

2. El tamaño del hijuelo utilizado entre 20 a $80 \mathrm{~cm}$. de altura no influyó en la diferenciación del prendimiento del pijuayo siempre y cuando se siembre con un almacenamiento de hasta 2 días.

3. Los hijuelos cuyos tamaños oscilan entre 20 a $40 \mathrm{~cm}$. de altura pueden soportar 4 días de almacenamiento sin variar significativamente el porcentaje de prendimiento.

4. $\mathrm{Al}$ aumentar el tiempo de almacenamiento de los hijuelos del pijuayo antes de la siembra (aislamiento), influye directamente en el prendimiento de la palma, disminuyendo la sobrevivencia.

5. Con almacenamientos mayores a 4 días, los prendimientos disminuyen significativamente, principalmente en hijuelos de mayor tamaño.

\section{RECOMENDACIONES}

1. Se puede utilizar para la propagación vegetativa Guilielma gasipaes B. hijuelos de 20 hasta $100 \mathrm{~cm}$ de altura, siempre y cuando el tiempo de almacenamiento no sobrepase los 2 días.

2. En casos excepcionales, cuando se presentan condiciones adversas para la plantación, debe seleccionarse hijuelos de 20 a $40 \mathrm{~cm}$ de altura, los que permitirán ser almacenados hasta 4 días.

3. Deben ensayarse estimuladores de enraizamiento en busca de mayores porcentajes.

\section{BIBLIOGRAFIA}

CABALlERO, M. 1973. Estadística práctica para dasónomos. México. Subsecretaría General Forestal y de Fauna. Dirección General del Inventario Forestal. 195 pág.

CALDERON, M. y CASTILLO, A. 1981. Evaluación y Lineamientos de Manejo de Suelos y Bosques para el Desarrollo Agrario de influencia de la Carretera Iquitos - Nauta. Capítulo 11. Ministerio de Agricultura, Dirección General de Forestal y Fauna. 320 pág. 
CALZADA, J. 1970. Métodos Estadísticos para la investigación. 3a Edición. Lima, Perú. Editorial Jurídica. 640 pág.

CALZADA, J. 1980. 143 Frutales Nativos, $1^{\text {a }}$ Edición. Lima, Perú.

CAMACHO, E. 1972. El Pelibaye. (Guilielma gasipaes) H.B.K.L - Bailey. Costa Rica. 106 pág.

CAMACHO, E. 1969. El Pejibaye como un alimento potencial de gran importancia en las familias campesinas de los trópicos amazónicos. 284 pág.

CAMACHO, V y SORIA, V. 1969. Palmettos de Pejibaye in Procepings of the Tropical Region. American Society Horticultural Sciences. 284 pág.

EEUWENS, C. 1978. Effects of organic nutrients and hormones on growth and developpment of tissues explants from coconut (Cocos nucifera) and date (Phoenix dactilifera) ehus cultural in vitro. Physiology lantarum. Dinamarca. 178 pág.

FERREIRA DO NACIMENTO S.A. CLEMENT C.R. y RANZANI, C.1980. "Contibuçao para o conhecimento de sistema radicular da Pupunheira (Bactris gasipaes) H. 13. K. Guilielma gasipaes (H.B. K.) Bailey” en Acta Amazónica 10 (2).

FOURNIER, A. "Pejibaje (Guilielma gasipaes) (H.B.K.) 1.h. Bailey”. San José, Costa Rica. s.f.

GONZALES, R. 1983. "Proyecto Frutales Nativos”. Estación Experimental San Roque. Exposición Iquitos. 4 pág.

GONZALES, G. y DOMINGUEZ, R. "Sistemas de propagación del Chontaduro (Guilielma gasipaes) Bailey”. Tesis Ing. Agrónomo Palmira, Col. Universidad Nacional de Colombia. 1977.

JOHANNESSEN, C. Pejibaye Palm.; Tielde, Process and labor costa. Economía Botany, 1966. 315 pág.

KOVOOR, A. "Palm tissue culture. State of the Art and its Applications to the Coconut”. Toma FAC. 1981. 69 pág. 
MORA URI, J. El ciclo de floración en pejibaye (Bactris gasipaes H.B. K.) y su posible manejo agronómico. Agronomía Costarricenses (C.R.) 1981. 119 pág.

MORA URPI y 1051. "Report on the feasibility of producing pejibaye in the chapare region of Bolivia', San José. 1983.

ONERN. Mapa Ecológico del Perú. Guía Descriptiva. Lima, Perú. 1976. 146 pág.

PATIÑO, V. El cachipay o pejibay (Guilielma gasipaes Bailey) y su papel en la cultura y en la economía de los pueblos indígenas de América Tropical, América Indígena. México 1958. 204 pág.

PATINO, V. "Historia Colonial y nombres indígenas de la palma Pejibay (Guilielma gasipaes) H . B. K. Bailey", en Revista Colombiana de Antropología. Colombia 1960. 72 pág.

PATIÑO, V. "Publicaciones del Jardín Botánico del Valle" en Boletín Divulgativo No 4. Cali, Colombia 1979. 74 Pág.

PEREZ, M. "Palmeras de la zona de Yurimaguas', Perú in FAC. (C.R.) CATIE. Reunión de consulta sobre palmeras poco utilizadas de América Tropical (1983, Turrialba) (C.R.) 1984. (Informe). San José. C.R. 1983. 166 pág.

PEREZ, M. "El Pijuayo en el Perú: manejos y usos". Yurimaguas, Loreto, Perú. 1985. 48 pág.

POPENDE, W y JIMENEZ, O. The Pejibaye, a neglected toood plantt of tropical Amen ca. The Journal of Hereditty. EE.UU 1921. 116 pág.

SEIBERT, J. The importance of alms to Latin América; Pejibaye a notable example. Ceiba. Honduras 1950. 74 pág.

SNEDECOR, C.N. y COCHRAN, W.G. Métodos Estadísticos. Octava impresión. México. Ed. Continental. 1981. 703 pág.

TISSERAT, B. Propagation of date palms by shoot tip cultures. Hortscience. EEUU. 1984. 231 pág. 
TISSERAT, B. Clonal ropagation; Palms in Vasil. Indra K. Cell. Culture and Somatic Cell Genetic of Plants. Volumen 1. Florida. 1984. 825 pág.

THOMAS, J. y DOMENECH. Atlas de Botánica. Edición Jover, Barcelona. 1987. 86 pág.

VALVERDE, M. "Descriptores de la Flor de Pejibaye (Bactris gasipaes H.B.K.) en cuatro poblaciones y sus posibles implicaciones fitogenéticas". Tesis Lic. Bio. San José C.R. Universidad de Costa Rica. 


\section{Grafico 1}

SUPERFICIE RESPUESTA DEL EXPERIMENTO FACTORIAL RESPECTO AL PRENDIMIENTO DE HIJUELOS DE Guilielma gasipaes Bailey

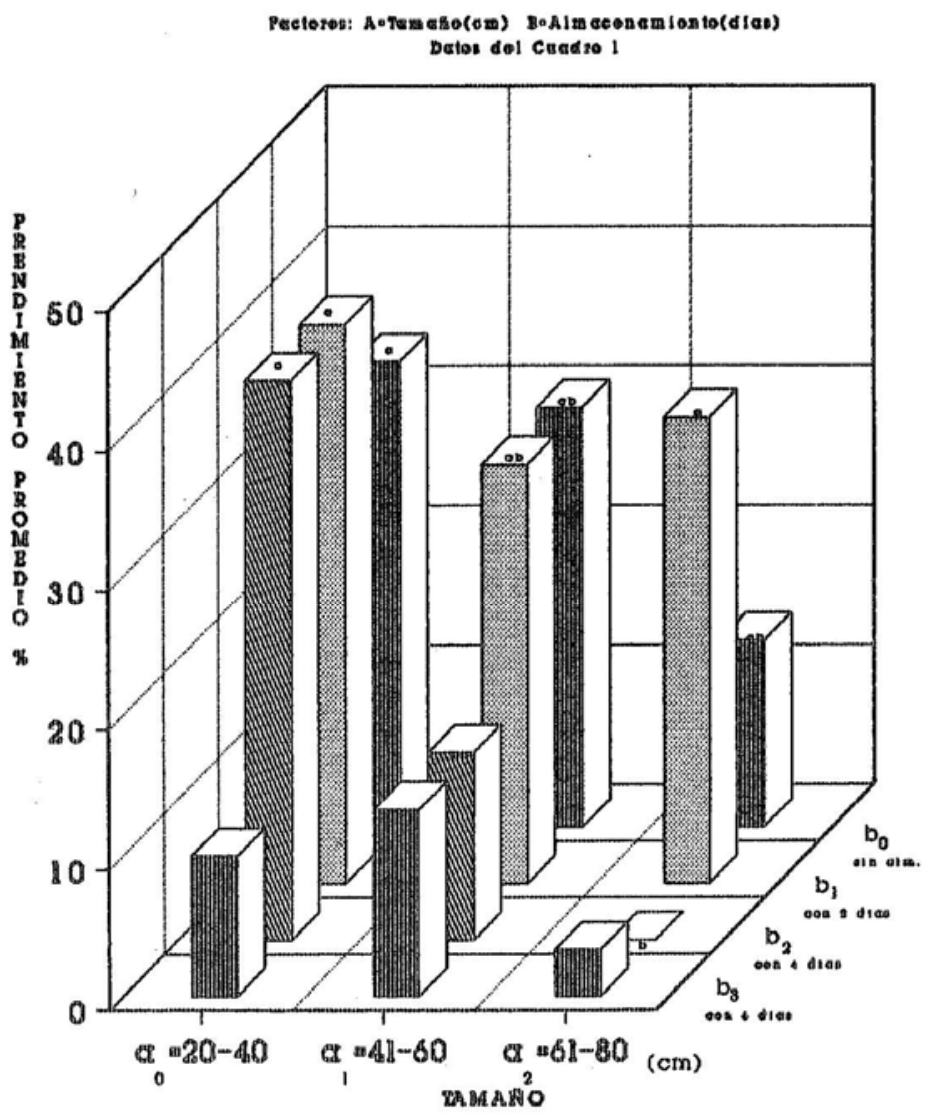

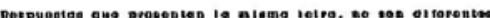




\section{Grafico 2}

SUPERFICIE RESPUESTA DEL EXPERIMENTO FACTORIAL RESPECTO AL PRENDIMIENTO DE HIJUELOS DE Guilielma gasipaes Bailey

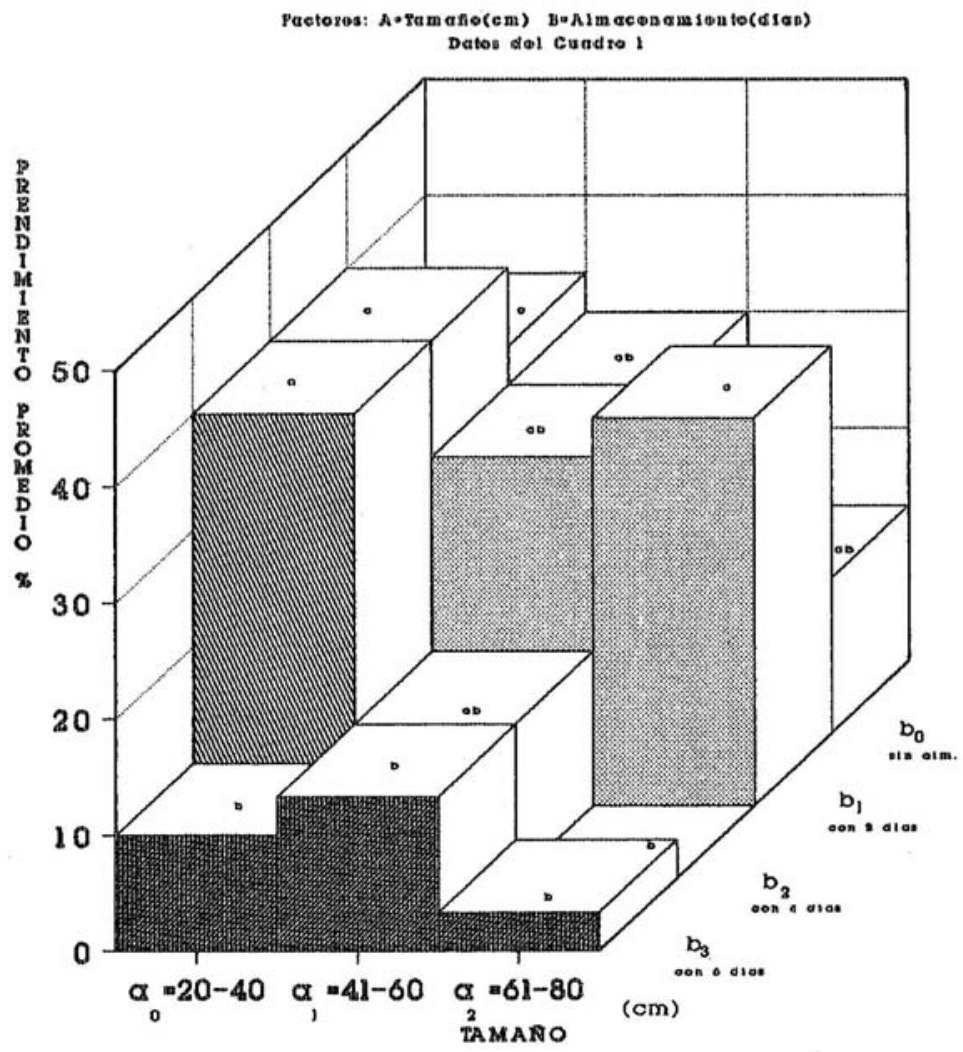

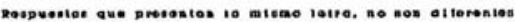




\section{Grafico 3}

PORCENTAJE DE PRENDIMIENTO

DE HIJUELOS POR TRATAMIENTO

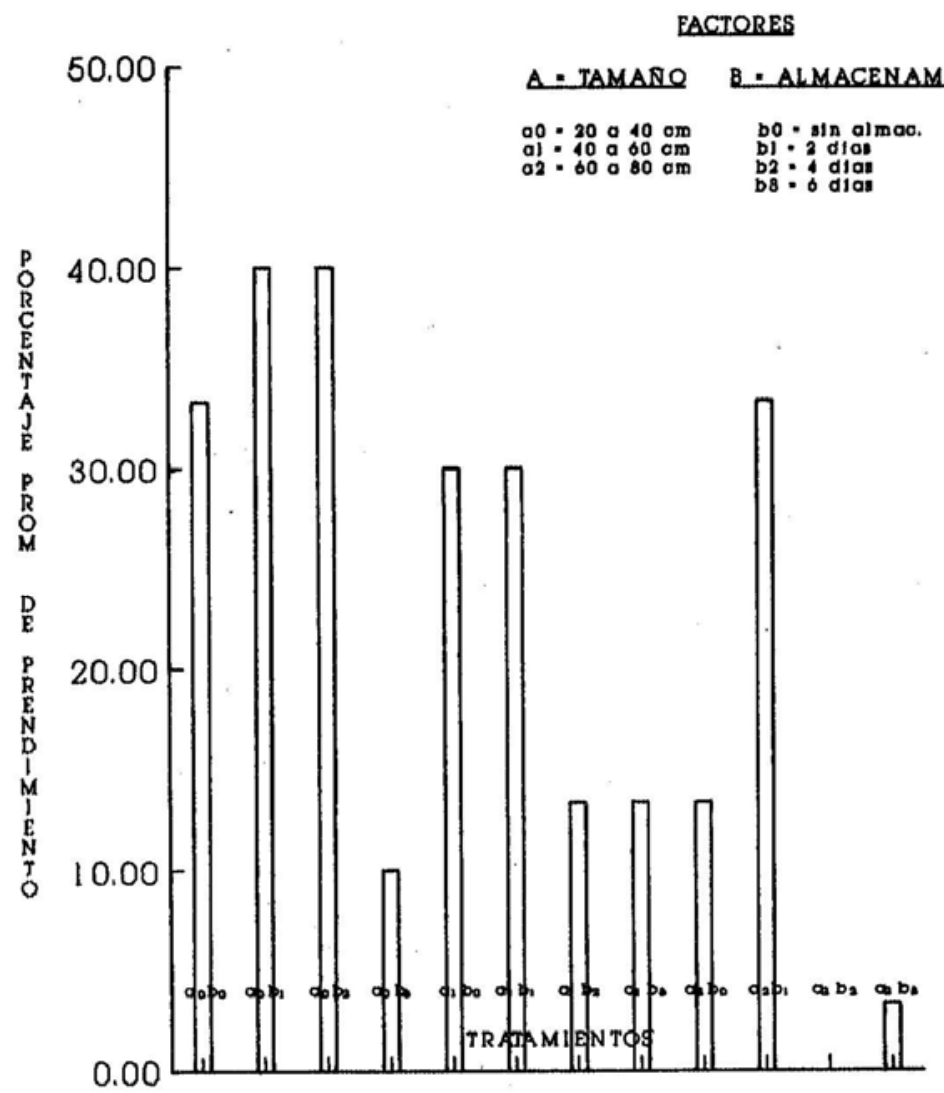

- Promedios sin dif.signtia nivel de $\delta \%$ 


\section{Cuadro 4}

CONTROL DE PRENDIMIENTO DE HIJUELOS A LOS 15,30,45 Y 330

DIAS PARA LOS TRES TAMAÑOS $(\mathrm{A}, \mathrm{B}, \mathrm{C})$ VS ALMACENTO
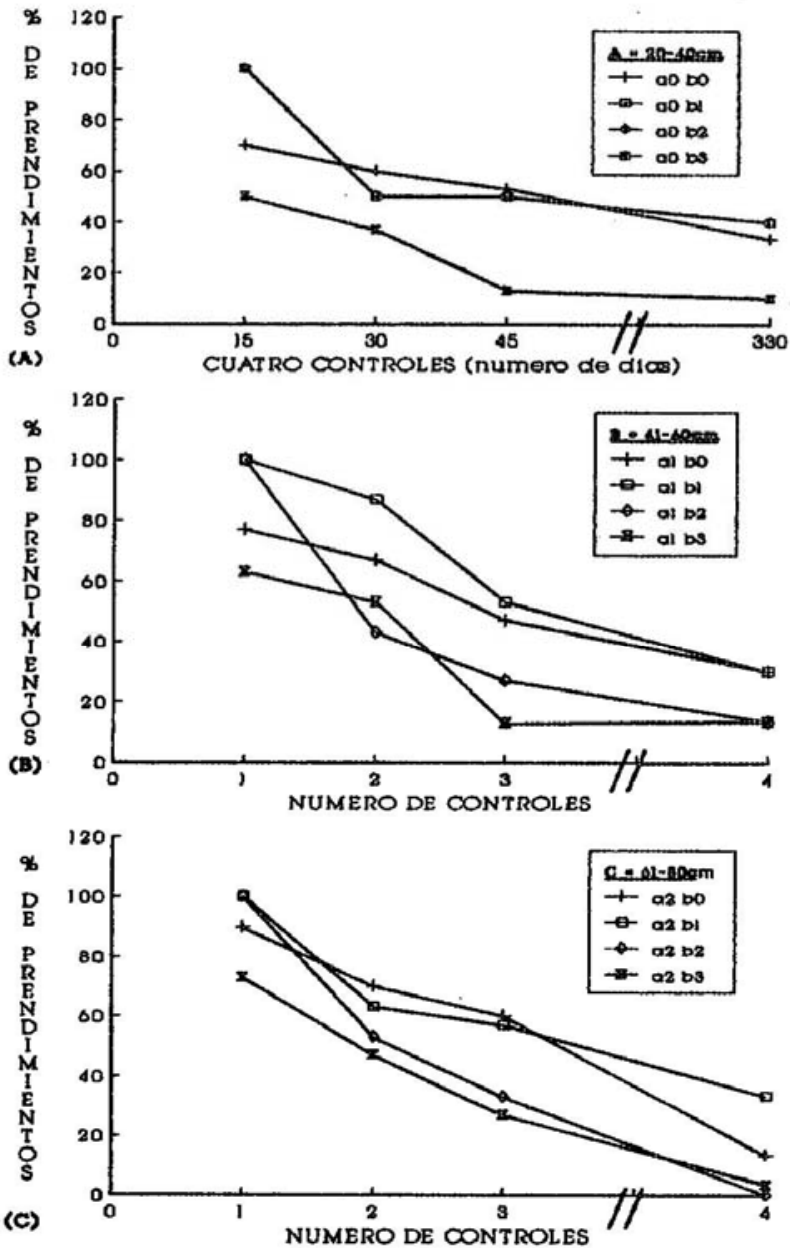

A. B, C CON DATOS DEL. CUADRO 7 